\title{
Pre-commercial procurement: a demand or supply policy instrument in relation to innovation?
}

\section{Charles Edquist ${ }^{1}$ and Jon Mikel Zabala-Iturriagagoitia ${ }^{1,2}$}

${ }^{1}$ CIRCLE, Lund University, Lund, Skåne, Sweden. charles.edquist@circle.lu.se

${ }^{2}$ Deusto Business School, University of Deusto, Donostia, Spain. jmzabala@deusto.es

\begin{abstract}
In 2006, the European Commission introduced the concept of 'pre-commercial procurement' (PCP) as an instrument to promote innovation and to mitigate grand challenges. One of the main motives for the support of PCP schemes was to use public needs as a driver for innovation. This concept was also introduced as a response to the need to reinforce the innovation capabilities of the European Union while improving the quality and efficiency of public services.

But what is meant by PCP? Is it a demand- or a supply-side instrument in relation to innovation? This is the research question addressed in this paper, the goal being motivated by the lack of academic discussion in this direction.

The paper is based on three cases, one from the Netherlands, one from the United Kingdom and one from Australia. These cases provide evidence that PCP is a matter of research and development (R\&D) funding of a targeted kind, geared toward very specific goals and in a focused way. This leads the authors to conclude that PCP is a supply-side policy instrument in relation to innovation. In this sense, they would like to raise a flag for going back to the origins of the PCP program and calling it a 'precompetitive R\&D program', rather than labeling it as an innovation procurement instrument.
\end{abstract}

\section{Introduction}

\footnotetext{
$A$ new European-level interest has recently emerged regarding demand-side approaches to innovation policy and, more specifically, the use of public demand as an engine for the development and diffusion of innovations (Edquist and Hommen, 1999). Edler and Georghiou (2007, p. 953) consider systemic policies (e.g. cluster policies and supply chain policies), regulation (e.g. standards and technology platforms), public procurement [i.e. research
}

and development (R\&D) procurement and innovation procurement] and support of private demand as the main demand-side innovation policy instruments. In 2004, the French, German and British governments issued a position paper to the European Council calling for the use of public procurement across Europe to spur innovation (French, German and UK Governments, 2004). This move continued and was manifested in various reports, including the Aho Group Report (Aho et al., 2006), which identified several application areas where demand-side 
policies could be used to a larger extent: e-Health, pharmaceuticals, energy, environment, transport and logistics, security and digital content.

'Public technology procurement' had long been practiced and discussed, as indicated in Edquist et al. (2000). Later, the language changed, and the term 'technology' was replaced by the concept of 'innovation', reflecting a widening in the content of the notion (Edquist and Zabala-Iturriagagoitia, 2012). A communication from the European Commission (2006a, 2006b) addresses the phenomenon called 'pre-commercial procurement' (PCP), which is a European Union (EU)-specific method for procuring R\&D services. ${ }^{1}$ The PCP scheme is based on the experiences within the United States, among others on the Small Business Innovation Research (SBIR) program (Small Business Innovation Development Act, 1982), but it is structured within the context of the European legislative package (Bodewes et al., 2009, p. 53).

The US SBIR program may be regarded as an example of an instrument similar to PCP practiced outside the EU, as it aims to generate multiple R\&Dbased knowledge outputs (Wessner, 2008). These $\mathrm{R} \& \mathrm{D}$ outputs may later reach the market through a mix of post-SBIR funding from a variety of sources such as venture capital, non-SBIR federal funds or foreign investment. The EU public procurement directives do not apply to PCP schemes (European Commission, 2008). Instead, PCP relies on using the $\mathrm{R} \& \mathrm{D}$ exemption in the EU procurement directives so as to adhere to the principles in the EU treaty as well as to EU state aid rules. ${ }^{2}$ Accordingly, PCP schemes do not conflict with current EU procurement regulations.

The very term pre-commercial procurement leads our thoughts in the direction of procurement of actual goods and services. As a result, PCP has often been presented as a demand-side innovation policy instrument (Berman and Squire, 2011; ECORYS, 2011; DG Connect, 2012; Lember et al., 2014). Because of this demand-side assumption, PCP is often mixed up with another policy instrument, namely public procurement for innovation (PPI). For example, Vinnova (the Swedish Governmental Agency for Innovation Systems), in a recent communication (where they build upon EU documents), refers to PCP as 'procurement of innovations' (Vinnova, 2007, p. 45). Edler and Georghiou (2007, p. 954) also mix the two terms when stating that 'the basic idea behind public pre-commercial procurement is that it targets innovative products and services for which further $R \& D$ needs to be done'. Similarly, Lember et al. (2014) consider PCP as a demand-side policy instrument that can support the development of innovation. In a case study conducted on the pre-commercial procurement in the field of security, ECORYS (2011, p. 7), it is concluded that 'PCP is a demand-based innovation scheme'. Finally, in June 2011, the European Commission organized a conference on innovation procurement in Torino (Italy), ${ }^{3}$ with several hundred participants, mainly policy makers, which reflects the increasing attention this topic is receiving in Europe. It was explicitly labeled a conference on 'Public Procurement of Innovation' but mainly addressed issues related to PCP. In addition to this, a considerable number of people, who have not reflected on this in detail, intuitively believe that PCP is a demand-side policy instrument in relation to innovation.

This paper intends to be a contribution to the so-far-nonexistent scientific literature on PCP. Indeed, there is no correspondence between the large number of policy reports written on the PCP scheme and the lack of academic discussion of it. Our goal is to respond to the research question formulated in the title of this manuscript: Is PCP a demand- or a supply-side policy instrument in relation to innovation? With it, we will try to advance the theoretical understanding of an area that has remained underconceptualized up to now, in order to provide an academic understanding of a well-spread phenomenon in the policy realm.

We base this article on empirical experiences by presenting three examples of PCP, one in the Netherlands, one in the United Kingdom and one in Australia. This is done in Section 3, where the three case descriptions are discussed in some detail. We ought to mention that we are fully aware of similar examples that have for long existed in the SBIR program in the United States. In fact, as acknowledged earlier, it may be said that the European experience might be influenced to a great extent by the American one. However, the goal of this paper lies in the qualitative analysis of the PCP. Accordingly, we have excluded SBIR cases, as these have already been extensively studied in the literature (Wallsten, 2000; Audretsch et al., 2002; Wessner, 2008; Link and Scott, 2010). However, we believe that the conclusions drawn in our study might also be of relevance to similar schemes in place in the United States and other countries with similar institutional settings, which have received longer attention in the scholarly literature.

Section 2 introduces the methodology. Based on the evidence from the cases (Section 3), Section 4 addresses the question of what is meant by PCP. The reason for including the conceptual discussion of PCP in Section 4 is related to the goal of the paper. Because we are interested in qualifying the character of PCP, it is not meaningful to introduce a conceptual discussion up front in the paper, where we still do not 
have evidence that suggests its demand or supply orientation. Finally, a discussion on the characteristics of PCP, as a demand- or supply-side policy instrument in relation to innovation, concludes the paper (Section 5).

\section{Methodology and introduction to the cases}

The methodological approach is exploratory. Information on each case has been compiled by accessing relevant secondary sources such as calls for tenders, scientific literature, policy documents and evaluations, and other written materials and reports.

The reason for focusing on these three cases lies in the experience that the three countries have gained from the application of PCP schemes (OECD, 2011). In addition, the number of PCP cases that may be considered is quite restricted, as many of them are still running or under definition, and hence available evidence is still limited. ${ }^{4}$ In fact, only a few countries have already started to fund pilot PCP initiatives in Europe. $^{5}$

Our approach should thus be regarded as qualitative and exploratory. Provided that our goal in this paper is to clarify the nature of PCP, the use of a qualitative approach seems sensible as qualitative studies provide the grounding for more rigorously structured research (Knafl and Howard, 1984). Given the still limited number of completed PCP experiences, there is not yet a comprehensive dataset to rely upon to conduct a quantitative assessment of this policy instrument. ${ }^{6}$ Thus, we have had to limit our information to the secondary sources of those cases where this information is available. In addition, the payoff of qualitative research is higher in fields that are not yet conceptually mature, which seems to be the case, at least in so far as an academic discussion is concerned.

The following section introduces, by means of a short description, the three cases considered in this paper. Despite the partial differences in their institutional (i.e. regulatory) environments, the reader will appreciate the uniformity of the PCP process in all three locations.

The first case refers to the development of a realtime dike observation and inspection system, an initiative launched by the Directorate-General of Public Works and Water Management as part of the Dutch SBIR program. The program was divided into a three-phase competition: feasibility, research phase and commercialization. The first two stages were totally funded by the contracting authority, but the respective company was in charge of financing the commercialization. Hence, commercialization was not actually included in the program. Two proposals were tested in this DigiDijk process. Although the program did not aim at producing new products on a large scale, these two prototypes were afterward transformed into commercial applications, financed by the firms.

The second case exemplifies one of the cases funded under the Small Business Research Initiative (SBRI) scheme in the United Kingdom. The 'Making Waves' initiative, supported by the Department for Business Innovation and Skills and the Technology Strategy Board, aimed to develop technologies capable of converting gestures or sign language into digital data so that people with communication difficulties could function effectively and independently.

The third case illustrates the procedure followed by the Smart Small- and Medium-Sized Enterprises (SMEs) Market Validation Program (MVP), one of the programs defined by the Victorian Government (Australia). It aims to identify the technology needs of Victorian public sector entities and to match them to the innovative capabilities of SMEs. It is a program whereby SMEs undertake R\&D activities to provide solutions that meet the needs of public agencies.

Table 1 summarizes these cases in more detail, according to a set of dimensions related to three distinctive aspects of procurement initiatives: the characteristics of the process, the procurer and the supplier.

1. PCP process

a. Challenge/need: illustrates the point of departure of the policy. What was the challenge/ problem/unsatisfied need?

b. Result of the procurement process: describes whether a product (material good or intangible service) or system was the intended result. Or were $R \& D$ results the intended output?

c. Degree of cooperation and type of call: was there an open call where potential suppliers could 'bid' in competition or was the call restricted to selected suppliers? This dimension shows whether the procurer cooperated with the supplier(s) during the PCP process, if there was communication (i.e. consultation/ dialogue/partnership) among them, etc. Did this differ in the various stages of the process?

d. Intended consequences: other intended consequences that the results had for the identified challenge, need, or problem.

e. Unintended consequences: other unintended consequences of the policy (e.g. regarding profits and exports). 


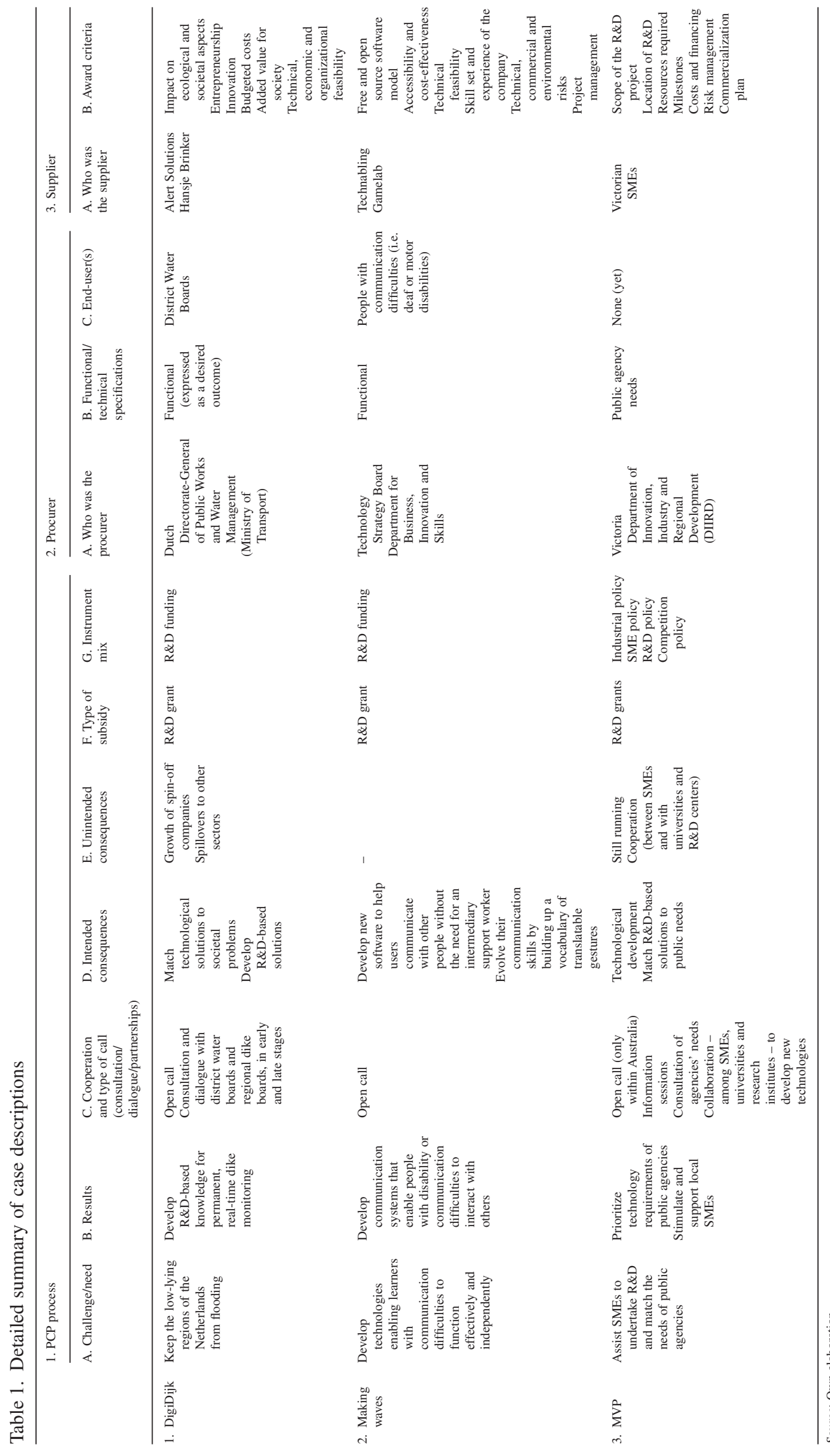


f. Type of subsidy: shows how the PCP process was funded, by R\&D subsidies, by promising (the purchase of) a future order, by offering economic rewards, etc.

g. Instrument mix: illustrates whether other policy instruments were also used as a complement to the PCP process.

\section{Procurer}

a. Who was the procurer: identifies the organization acting as a procurer of the intended result.

b. Functional/technical specifications: illustrates whether the procurer developed functional or technical specifications, or both, prior to launching the PCP process. How did the procurer develop the specifications?

c. End-user: identifies who was the end user of the (intended) result of the PCP.

3. Supplier

a. Who was the supplier: identifies the organization/firm acting as the supplier of the intended result.

b. Award criteria: defines the criteria by which the supplier was awarded the contract.

Following these dimensions, Sections 3.1, 3.2 and 3.3 contain more thorough descriptions of each case.

\section{Case studies}

The following three subsections provide a broader description of the stages and evolution of each policy initiative.

\subsection{Digital dike (DigiDijk) - real-time dike observation and inspection}

The Dutch government implemented its SBIR in 2004, a program with the aim of finding innovative solutions to societal issues within a short time span (NL Agency, 2011). Although the name of the program may suggest that SMEs constitute its target group, any company, regardless of its size, stands a chance in SBIR tendering procedures (NL Agency, 2011, p. 2).

The US SBIR program, which was the role model for the Dutch SBIR, was created in 1982 through the Small Business Innovation Development Act (1982, p. 97) and aimed to:

- stimulate technological innovation,

- use small business to meet federal R\&D needs,

- foster and encourage participation by minority and disadvantaged persons in technological innovation, and
- increase private sector commercialization innovations derived from federal R\&D.

Initiated in 2004, the Dutch SBIR program significantly increased its budget from $€ 0.2$ million in 2004 to $€ 26.3$ million in 2010 (NL agency, 2011, p. 2; Sloth, 2011, p. 13). The procedure in the Dutch SBIR starts with a public authority identifying a specific challenge or a societal issue for which new solutions are needed, and making a budget available for it (NL Agency, 2011, p. 4). ${ }^{7}$ Then the public authority launches an open competition within a specific tender period. All competitions are expressed as a desired outcome or challenge/need to be solved rather than a detailed set of specifications. An independent evaluation committee reviews the proposals according to the following criteria: impact on the societal issue, economic prospects, ecological and societal aspects, contribution to the solution of public demand and entrepreneurship, (technological) quality and degree of innovation, budgeted costs and added value for society (NL Agency, 2011, p. 4; Sloth, 2011, p. 15).

As in the US SBIR, contracts are awarded in a three-phase competition: feasibility, research phase and commercialization. The Dutch-contracting authority fully funds the first two phases through a fixed-cost R\&D contract, while the company must finance the commercialization. In other words, the commercialization is actually not part of the PCP program. The possible resulting intellectual property rights (IPRs) remain with the company.

During the feasibility stage (phase 1), companies must demonstrate the practicability of their proposal, that is, establish the scientific and commercial potential of their idea to solve the identified need or challenge (maximum of six months, maximum of $€ 50,000$ per project). At this stage, the technical, economic and organizational viability of the project idea is defined. The contracting authority decides which projects will be commissioned as phase 2 contracts. In the research phase (phase 2), R\&D activities are carried out until a first, noncommercial prototype is obtained (maximum of two years, maximum of $€ 450,000$ per project). Finally, in phase 3 , the companies start preparing their prototypes/ solutions for market launch. However, as pointed out earlier, this phase is not financed by the Dutch SBIR.

Here, we will focus on one of the cases funded by the SBIR in the Netherlands (Roos, 2011), a typical Dutch one: real-time dike observation and inspection. As is well-known, dikes are crucial elements to keep the low-lying regions of the Netherlands from flooding. Some dikes have been broken: Wilnis in August 2003 and Stein in January 2004. The DirectorateGeneral of Public Works and Water Management 
(Ministry of Transport) decided that there was a need to find new solutions for monitoring dikes, and he saw an opportunity to achieve it through the SBIR. The 'DigiDijk', a real-time dike observation and inspection project, was started in 2007. The invitation for bids to the private sector was simple and reflected a broad challenge: Is it possible to apply new technologies for conducting permanent, real-time dike monitoring and early detection of weak spots?

Of the 21 proposals received for phase 1, five were allocated funding for a feasibility study. Of these proposals, two were selected for further development in April 2008 to create a prototype in collaboration with several district water boards. The two proposals - both start-ups - were 'GeoBeads' (from Alert Solutions) and 'Monitoring of Dikes from Space' (from Hansje Brinker). ${ }^{8}$ GeoBeads revolved around measurement instruments (sensors) installed within the structure of the dike itself, which sent data to a central station (NL Agency, 2011). The Monitoring from Space proposal provided dike inspectors with software enabling them to detect, by satellite footage, any type of movement and alteration in size. While GeoBeads was particularly interesting for use on a smaller scale, Monitoring from Space offered added value when used on a larger scale. The two systems complemented each other, even if that was not the original intent.

The involvement of water boards from the start of the PCP project did not guarantee that the solutions would be purchased. In fact, it took a lot of commercialization efforts for the companies to find their first customers. In this sense, the two companies benefitted from the networks of the contracting authority with water control boards, and they built on the IPR they got from the DigiDijk project. Alert Solutions sold the GeoBeads system to five district water boards. Hansje Brinker also sold its system to Hondsbossche en Pettemer Zeewering, the highest dike in the Netherlands. Nowadays, both companies have their products in the market, and they can expand to other application areas on the basis of their unique product basis. Something that holds true for both innovations is that they can also be used for purposes other than those originally intended, including opportunities in the building sector, for example, monitoring risks in and near excavation sites (NL Agency, 2011, p. 5).

\subsection{Making waves: gesture-based communication system}

A country that has adopted a more hands-on approach toward the promotion of procurement policies is the United Kingdom. It introduced the SBRI in 2011, earmarking a share of the government's procurement budget for SMEs through competitive R\&D contracts (OECD, 2011, p. 41). The SBRI aims to use government procurement to drive innovation by providing business opportunities for innovative companies to solve the specific challenges facing government departments and public sector organizations. The goal is to create R\&D in intensive SMEs and to raise their awareness of the future commercial benefits that the research base can offer. ${ }^{9}$

The SBRI is one of the tools that the Technology Strategy Board uses to enhance innovation in the United Kingdom. The Technology Strategy Board, which is sponsored by the Department for Business, Innovation and Skills, is a business-led executive nondepartmental public body, established by the government. In order to increase economic growth and improve the quality of life, its role is to promote and support R\&D and exploitation of technology and innovation for the benefit of UK business.

We focus on the 'Making waves: gesture-based communication system' initiative of the UK SBRI. This SBRI competition, launched on January 10, 2011, sought the development of location and gesturebased communication systems that could enable learners with disability or communication difficulties to interact with mobile technologies, resulting in the production of text and/or audio input or execution of commands (Innovate UK, 2012). ${ }^{10}$

The competition was structured in two phases. Phase 1 (proof of concept) was intended to show the technical feasibility of the proposed concept. The SBRI funding covered $100 \%$ of all eligible costs for a maximum of six months, with a total amount of $£ 250,000$ for this phase 1 . Phase 2 (development of prototype) was intended to develop and evaluate prototypes or demonstration units from the most promising proposals in phase 1. Eleven evaluation criteria were defined, going from the possibility of developing a free and open source software model, to assessing the accessibility, technical feasibility and cost-effectiveness of the solutions or the skill sets of the candidate companies (Technology Strategy Board, 2011). ${ }^{11}$

The deadline for the submission of proposals was set (March 15, 2011) two months after the call was announced, so applicant companies were expected to respond rapidly. The contracts with the successful candidates were expected to be issued on April 21, 2011 , and the feasibility of the solutions was expected to be assessed by October 28, 2011 (Technology Strategy Board, 2011).

Three candidates were funded for phase 1 , and after a period of rigorous review and assessment, the two successful companies that progressed to phase 2 were 
Gamelab (London) and Technabling Ltd. (funded at the University of Aberdeen). Gamelab developed an interactive gesture recognition program (uKinect) based on Microsoft Kinect technology. The 'Portable Sign Language Translator' from Technabling enabled nonsigners to communicate with signers by translating their signs into text. This was a portable, flexible and customizable solution, so it could accommodate a range of different sign languages and work with a wide variety of handheld camera-enabled devices (e.g. laptops, smartphones and tablet devices). These two projects on gesture recognition allowed the user (with communication difficulties, either deaf or motor disabilities) to 'talk' to the device in sign language. The gestures were then captured, stored and software processed to recognize sequences of user gestures through a locally stored library of core concepts or words. These were then assembled into sentences and outputted as text in real time (Innovate UK, 2012).

Many in the British sign language community are showing interest in how uKinect and the Portable Sign Language Translator may be used in both educational and social settings, so this could be an important potential market. ${ }^{12}$ However, both companies are still working to advance their technologies to capture the whole set of British sign language and to transform their prototype into a fully fledged product affordable for the average person. ${ }^{13}$

This case illustrates how this type of public support for the satisfaction of a social need does not imply any real purchase but only funding of $R \& D$ activities. In fact, the call from the Technology Strategy Board explicitly states that if the "technology development is successful, every effort will be made to source and purchase the innovative product from the organization. However there is no commitment to do so or to purchase any specific quantity in this phase of the competition' (Technology Strategy Board, 2011, p. 4).

\subsection{Smart SMEs MVP}

The Smart SMEs MVP (AU\$28 million) is one of the programs included in the Victorian Government Innovation Statement (Australia), managed by the Department of Innovation, Industry and Regional Development. On the one hand, the aim of the MVP is to identify the needs of Victorian public sector entities and to match them to SMEs with the specific potential capability to meet those needs. On the other hand, and according to Berman and Squire (2011, p. 98), it also aims to assist these SMEs to create and commercialize new intellectual property and develop globally competitive technology, products and services.
We acknowledge that PCP is an EU-specific program. However, it might be a good idea to remember that there are also differences in Europe about what is meant by PCP. Different support mechanisms have been implemented across the EU to embody PCP as a policy instrument, for example, the Dutch SBIR program, the British SBRI program, the Flemish Action Plan on Procurement of Innovation, the Swedish Forska \& Väx and the Hungarian ÉszakAlföld program (Sloth, 2011). By including a case from a non-EU country that has nevertheless used the same PCP scheme, we want to put this particular policy instrument into perspective.

Berman and Squire (2011, p. 98) qualify it as a 'demand-driven programme ... [which] differs from a traditional supply-side grant programme in that the MVP invites public-sector entities to identify their priority technology requirements (thereby becoming the client of the programme) and SMEs are given the opportunity to undertake R\&D in an environment in which they are able to prove their new technology in a real-world customer context'. However, these authors also consider the program to be one that revolves around a technology-pull mechanism, as 'an [public] entity's demand for particular types of R\&D for innovation pulls the need for these technologies onto the market' (p. 99). Let us come back to this later to provide some clarification (Section 4).

As in the previous cases, the MVP also takes the US SBIR program as a starting point, sharing some of its rationales. Nonetheless, it differs from the latter in many ways. First, the MVP encourages voluntary participation by public sector entities. Second, it is open to about 300 public agencies and organizations in the state of Victoria. Last, it is open to SMEs with fewer than 200 employees. The MVP involves two rounds of grants over a four-year period, and it is divided into three stages: (1) technology requirement specifications, (2) feasibility study and (3) proof of concept. ${ }^{14}$

The process begins with Victorian public agencies identifying a specific need associated with their mission and for which there is no commercial solution on the market. Approved TRS are then included in a call for proposals inviting SMEs to propose an R\&D-based solution to the need. During the second stage, SMEs develop their own concepts, showing that they propose a new solution that can be a potential basis for intellectual property. Successful firms receive a grant of up to AU\$100,000 (from the DIIRD) to develop a feasibility study. The MVP offers the possibility of funding more than one SME for the same TRS, which increases competition among bidders. This feasibility study (three months) is assessed by the host entity (i.e. agency defining the 
need) together with industry experts and the DIIRD. The assessment criteria include the scope of the R\&D project, the main location for the development of the $\mathrm{R} \& \mathrm{D}$, the resources required, key milestones, staff, costs and financing, risk management strategy, and commercialization plan.

If the proposed project is approved, the SME is given the opportunity to prove its concept. In this last stage, the SME is supported with up to AU\$1.5 million over two years. The firm retains all the IPR while the funding entity formulating the problem retains a license to use them. The successful completion of the proof of concept finally leads to a demonstration of the solution. Once the host entity accepts the developed solution, the R\&D obligations of the program are finished - with no guarantee from the public agency that procurement will follow (Berman and Squire, 2011, p. 100).

When the MVP was announced in August 2008, several information sessions were conducted to disseminate the content of the program. As the assessment criteria stated earlier reflect, collaboration (among SMEs or between SMEs and universities or research institutes) was not included as one of the key principles for the selection process. However, 85 SMEs (69\% of all submissions) indicated an intention to collaborate with another enterprise, a university or publicly funded research facility in the development of their solution. Hence, collaboration was an important determinant in the formation of the proposals (Edquist and Zabala-Iturriagagoitia, 2012).

The first round of the program opened in 2009. For stage 1, 74 TRS were submitted by 27 public sector entities. Nineteen TRS from 11 agencies were shortlisted for stage 2, which attracted 124 submissions from Victorian SMEs during the feasibility study. ${ }^{15}$ These were sent to the respective host agencies for their selection. After evaluation of the feasibility studies, nine projects progressed toward the proof-of-concept phase. As to the second round, this was opened in July 2010, and the selected six proofof-concept projects are expect by the end of 2014. ${ }^{16}$

The first round of the MVP is not yet finished, as proof-of-concept projects are still running and expected to be finished by the end of 2013; hence, a comprehensive assessment of the effects cannot yet be made. However, some interesting trends can be observed, for example, the high level of intended collaboration of the received proposals (69\%) and the high representation of SMEs with fewer than seven employees (Berman and Squire, 2011, p. 101). In addition, a relatively high number of proposals (70) were received from SMEs with no prior R\&D performance history. This is significant, as it indicates that the program has supported the entry of new actors into the innovation system.

\section{What is PCP?}

PCP is receiving increasing attention in Europe. However, to date, we cannot refer to any academic studies in this area - which explains why most references included in this paper come from official reports, white papers and national policy initiatives. ${ }^{17}$ This section provides an answer to the question we posed at the beginning of this paper, regarding the demand- or supply-side character of PCP.

$\mathrm{PCP}$ is defined as 'a process by which public authorities in Europe can steer the development of new technologically innovative solutions that can address their specific needs' (European Commission, 2006b, p. 2). One of the rationales for the support of PCP policies is to provide the missing link in the development of completely new 'yet-to-be-designed' technology research in Europe (European Commission, 2006a, p. 18). PCP is regarded by the European Commission (2006b) as an interactive learning multistage, multicompetitor process/method for procurers, suppliers and users, as the capabilities of new technological developments on the supply side are intended to match the needs on the demand side (OECD, 2011). As the three cases presented in Section 3 illustrate, PCP practices, in general, are managed in three steps:

1. Solution exploration phase ( $\sim 6$ months): where a number of offers from competing suppliers are selected.

2. Prototyping phase ( $\sim 2$ years): where the chosen suppliers develop their own models or solutions in parallel.

3. Testing phase ( $\sim 2$ years): where at least two suppliers remain to ensure future competition in the market. The solutions are validated through field tests.

The PCP process (as outlined by the European Commission, 2008) starts with a pre-commercial tendering initiated by a public agency, which intends to provide a solution to a societal or agency need/ challenge by means of curiosity-driven research. Once the feasibility studies have been received from candidate companies for this solution exploration (phase 1), they are subjected to an intermediate evaluation according to a predefined set of criteria. Some of the candidate companies are shortlisted for a second phase, in which they conduct the required R\&D activities until a first, noncommercial prototype is obtained. Once the assessment of these prototypes is finished, some of the companies are invited to test 
a limited number of these prototypes under field conditions (phase 3). This is where the PCP process ends.

After the field tests that conclude the PCP process, a separate regular procurement tendering may take place. It may be pursued either by the same public agencies funding the PCP scheme or by other organizations (public or private) interested in the results of the PCP process. However, this regular procurement tendering or commercialization is not part of the PCP scheme. The firm that developed the solutions may also try to commercialize its solutions on its own. In PCP, the public purchaser does not reserve the R\&D results exclusively for its own use (European Commission, 2008). In contrast, it is the supplier that solely owns the IPR or shares them (after negotiation) with the corresponding public agency. ${ }^{18} \mathrm{We}$ will come back to this point in the concluding section.

From our point of view, the language used in the third phase of the PCP process is puzzling. The European Commission (2008, p. 8) calls this phase 'original development of a limited volume of first products/services in the form of a test series'. However, testing a prototype (or a series of prototypes) under field conditions is not the same as developing a product innovation. Innovations are defined as new creations of economic and societal significance, primarily carried out by firms (but not in isolation). They include product innovations as well as process innovations. Product innovations are new or improved - material goods as well as new intangible services; it is a matter of what is produced. Process innovations are new ways of producing goods and services. They may be technological or organizational; it is a matter of how things are produced. Hence, to qualify as an innovation, the product or process needs to be commercialized, that is, launched on the market, a feature that is not completed by prototype testing. A prototype is an effective model or archetype that needs to work under certain conditions. A prototype (or a limited number of copies of it) is only intended to demonstrate its effectiveness in mitigating a certain challenge/need and its suitability for production according to the required quality standards (European Commission, 2006a, p. 21). It is not produced on a large scale, that is, it is not commercialized and neither is its commercial viability proven.

A scheme that shared many of the characteristics to the $\mathrm{PCP}$ is the 'precompetitive R\&D programs' created by the EU in the 1980s (European Commission, 2006a). The main goal of these precompetitive R\&D initiatives was to conduct $R \& D$ activities that were "distanced from the market, being focused on "generic" or "enabling" technologies rather than the development of final-use products targeted on specific markets' (Quintas and Guy, 1995, p. 326). As Quintas and Guy point out, these programs 'covered a spectrum of work from applied research through to near-market development ... [ [they were] not expected to produce commercially usable process technologies or products, but rather to reach the stage of demonstrating feasibility or providing research prototypes' (ibid).

The Dutch and British cases illustrate that a PCP project may (but not necessarily will) have an impact on the development of product innovations, despite the fact that this is not part of the PCP scheme. The intention is to induce companies to create R\&Dbased solutions to societal challenges (e.g. avoiding flooding and allowing people with communication difficulties to be able to communicate effectively and independently), not to achieve commercialization of new products. It is a matter of public funding of applied R\&D (i.e. 'D' rather than ' $R$ ') that is socially relevant - in the sense that it takes its point of departure from a specific challenge. The PCP form of R\&D funding is very 'purpose oriented', 'targeted' or 'focused' and certainly not a matter of general R\&D funding without a specific purpose. It can thus be concluded that PCP is a supply-side policy instrument in relation to innovation. However, at the same time, it is a demand-side instrument in relation to $\mathrm{R} \& \mathrm{D}$, as it only intends to influence the production of R\&D outputs. In this sense, we would like to raise a flag for going back to the origins of the PCP program and calling it a precompetitive R\&D program. PCP may still influence innovation processes but only in an indirect and mediated way by being publicly funded $R \& D$, which in the context of this paper we label as 'targeted R\&D'. And public R\&D funding as such (including PCP) is certainly a supply-side innovation policy instrument, when it influences innovation processes.

\section{Conclusions and discussion}

This paper aims to answer whether PCP can be regarded as a demand- or supply-side innovation policy instrument. The paper follows an exploratory methodological approach based on secondary sources through which information on PCP experiences is available. In particular, we base our conclusions on the analysis of three PCP case studies, one in the Netherlands, one in the United Kingdom and one in Australia. PCP is a topic on which many policy reports have been written, but there is still no solid empirical base, at least in so far as the EU is concerned. In addition, there are still no profound academic and theoretical contributions regarding PCP. 
Therefore, this paper intends to advance the theoretical understanding of an area that has remained underconceptualized. Accordingly, we try to provide a scientific understanding of a phenomenon that is well spread in the policy realm.

PCP concerns the R\&D phase before commercialization (European Commission, 2008, p. 2). It is an approach to procuring $\mathrm{R} \& \mathrm{D}$ services, one which involves risk-benefit sharing but excludes State aid (European Commission, 2006b; European Commission, 2008, p. 6). This implies that the private supplier shares the risk of the R\&D, and that the public authority is not required to purchase the good, service or system that may (or may not) result from the R\&D (Sloth, 2011). Public authorities and industry thus share the risks and benefits of the R\&D needed to develop new R\&D-based knowledge. These R\&D results may (or may not) later lead to product innovations that may outperform those already available in the market (European Commission, 2008, p. 3).

PCP is an approach that aims to support R\&D and the prototyping/demonstration of new products (goods and services) by providing funding to a company, usually an SME. PCP refers to the acquisition of expected research results and entails direct public R\&D investments. However, it does not support further commercialization in terms of providing funding for a company to invest in manufacturing capability, increase the scale of its production facilities, or market and promote its product. The company has to find other funding for this. Just like the precompetitive $\mathrm{R} \& \mathrm{D}$ programs implemented in Europe in the 1980s, PCP does not imply any intention or guarantee from the public agency funding the PCP initiative to buy R\&D services/solutions that may result (Quintas and Guy, 1995; OECD, 2011). This was evidenced by the three cases in Section 3, in which the calls for solution exploration proposals were formulated as addressing public agency or societal challenges/needs.

Nevertheless, participation in PCP programs has helped some companies to attract such investment from the private sector (Bodewes et al., 2009). Therefore, while PCP does not directly provide support for these activities, it can help companies to leverage additional funding because the process of product development and testing has been de-risked. This removes, at least in part, a key potential problem in terms of information provision in the innovation process, that is, the technological uncertainty associated with new product development and whether this will be successful.

As shown in the introduction to this paper, PCP is often considered to be a demand-side innovation policy instrument. Based on the evidence gathered in this paper, though, it can be concluded that the classification of PCP as a demand-side policy instrument should be questioned. Demand-side innovation policies are defined as 'a set of public measures to increase the demand for innovations, to improve the conditions for the uptake of innovations or to improve the articulation of demand in order to spur innovations and the diffusion of innovations' (Edler and Georghiou, 2007, p. 952). As the three cases have illustrated, PCP aims at providing (R\&D-based) solutions to existing challenges but without identifying a buyer that may indeed contribute to the further uptake, articulation and diffusion of innovations, as indicated by the previous definition. Commercialization cannot be regarded as part of the PCP process, as none of the procurers funded the commercialization of the selected solutions, nor was there any commitment from the funding public agencies to buy the resulting product. The procurements (selling and buying) that may follow PCP processes may be regarded as examples of the acquisition of off-theshelf products (the prototypes for which have been developed in the PCP process), that is, it becomes a matter of regular procurement. ${ }^{19}$ Without the PCP interventions, however, these prototypes may not have existed or perhaps existed much later.

PCP involves public financing of R\&D and thus has to be considered a supply-side policy instrument in relation to innovation. Supply-side policy instruments address those determinants that intend to increase the operative efficiency of markets and industries. In this sense, fiscal measures, support for training and mobility, grants for industrial R\&D, information and brokerage support, and networking measures entail some examples of supply-side policy instruments (Edler and Georghiou, 2007). Accordingly, PCP may be defined as a technology push rather than a market pull instrument in relation to innovation. However, PCP may be considered a demand-side policy instrument in relation to $\mathrm{R} \& \mathrm{D}$. This conclusion may be also extensible to other similar programs such as the SBIR in the United States.

PCP can be integrated into a broader policy instrument mix, shortening time to market and encouraging market acceptance of new solutions when seen as part of a coordinated policy framework (European Commission, 2008). In this sense, PCP can complement other innovation instruments such as grants, tax incentives, access to finance, joint technology initiatives, venture capital investments, demand-based foresight, regular procurement, development/modification of regulations and norms, standard setting, innovation vouchers, etc. (European Commission, 2006b; Edler, 2009; Flanagan et al., 2011; OECD, 2011). Such instruments may be combined in a mix to solve or mitigate 
problems that would otherwise be subject to innovation policy intervention (Smits and Kuhlmann, 2004; Smits et al., 2010; Edquist, 2011; Wieczorek and Hekkert, 2012). ${ }^{20}$

Let us add a few comments about different kinds of procurement that may be parts of such innovation policy instrument mixes. We have already seen that PCP and regular procurement may supplement each other. The introduction mentioned that PCP is often mixed up with PPI. ${ }^{21}$ Obviously, PCP is not the same as PPI because no placement of orders for products is involved in the former. However, the combination of PCP and regular procurement may be a substitute for PPI because the two alternatives may cover the same 'parts' in an innovation process as a whole. If the result (prototype) of the PCP process needs further development before it can constitute a finished product, PPI can also be a supplement to PCP.

That PCP is not a demand-side innovation policy instrument certainly does not diminish its importance. It may be crucial as a demand-side R\&D policy instrument in efforts to mitigate global challenges and societal problems at the same time as satisfying human needs. It may do so as a targeted, demand-side R\&D policy instrument. It is therefore excellent that PCP is currently receiving increasing attention and is being developed as a part of comprehensive policy instrument mixes.

\section{Acknowledgments}

Preliminary versions of this paper were presented at the Annual Eu-SPRI conferences in Karlsruhe (Germany), June 2012, and Madrid (Spain), April 2013, at DG Enterprise and DG Research and Innovation in Brussels (Belgium), November 2012, and at a keynote speech at the Organization for Economic Co-operation and Development Expert Workshop on the Measurement of PPI in Paris (France), February 2013. The authors are grateful to the European Commission for providing the funding to develop the AEGIS project (Advancing Knowledge-Intensive Entrepreneurship and Innovation for Economic Growth and Social Well-Being in Europe), grant agreement number 225134. Jon Mikel ZabalaIturriagagoitia acknowledges financial support from the Basque Government Department of Education, Language Policy and Culture, and Charles Edquist acknowledges support from the Rausing Foundation. We are grateful to André Roos, from the Dutch Ministry of Economic Affairs, Agriculture and Innovation for facilitating information on the Dutch case. We are indebted to Fergus Harradence (Department of Business, Innovation and Skills, UK), Katarina
Krell (Managing Director of Greenovate, Europe), Charles Wessner (National Academy of Sciences, US), Lieve Bos (Directorate General Communication Networks, Content and Technology), Kirsten Bound (Nesta, UK) and two anonymous referees for their comments on earlier versions of the article. The content of the article reflects the opinions and views of the authors alone.

\section{References}

Aho, E., Cornu, J., Georghiou, L., and Subira, A. (2006) Creating an innovative Europe. Report of the Independent Expert Group on R\&D and innovation appointed following the Hampton Court Summit and chaired by Mr. Esko Aho. European Communities, Brussels, January 2006.

Audretsch, D.B., Link, A.N., and Scott, J.T. (2002) Public/ private technology partnerships: evaluating SBIRsupported research. Research Policy, 31, 1, 145-158.

Berman, T. and Squire, M. (2011) Demand-side innovation policies in Australia. In: OECD (ed.), (2011), DemandSide Innovation Policies. Paris: OECD Publishing. pp. 95-113.

Bodewes, H., Hargeskog, S.E., Müller, L., Ottolander, M., Thevissen, P., Veys, C., and Widmark, N. (2009) Exploring public procurement as a strategic innovation policy mix instrument. EU project OMC-PTP. Available: http:// cordis.europa.eu/fp7/ict/telearn-digicult/presentation-2 .pdf (last access October 2013).

Borrás, S. and Edquist, C. (2013) The choice of innovation policy instruments. Technological Forecasting and Social Change, 80, 8, 1513-1522.

Bovis, C. (1998) The regulation of public procurement as a key element of European economic law. European Law Journal, 4, 2, 220-242.

DG Connect. (2012) FP7 ICT WP2013. Objective 8.2 technology-enhanced learning. Unit G4 'Skills, Youth and Inclusion', European Commission (Luxembourg). Available: http://www.ec.europa.eu/information_society/ events/ (last access October 2012).

ECORYS. (2011) Study on pre-commercial procurement in the field of security. Within the Framework Contract of Security Studies - ENTR/09/050. Final Report. Rotterdam, November 2011.

Edler, J. (2009) Demand policies for innovation in EU CEE countries. Manchester Business School Working Paper No 579, The University of Manchester.

Edler, J. and Georghiou, L. (2007) Public procurement and innovation - resurrecting the demand side. Research Policy, 36, 949-963.

Edquist, C. (2011) Design of innovation policy through diagnostic analysis: identification of systemic problems (or failures). Industrial and Corporate Change, 20, 6, $1725-1753$

Edquist, C. and Hommen, L. (1999) Systems of innovation: theory and policy from the demand side. Technology in Society, 21, 63-79. 
Edquist, C., Hommen, L., and Tsipouri, L. (eds) (2000) Public Technology Procurement and Innovation. Boston/Dordrecht/London: Kluwer Academic.

Edquist, C. and Zabala-Iturriagagoitia, J.M. (2012) Public procurement for innovation as mission-oriented innovation policy. Research Policy, 41, 10, 17571769.

European Commission. (2006a) Pre-commercial procurement. A missing link in the European innovation cycle. European Commission, March 2006.

European Commission. (2006b) Pre-commercial procurement. Public sector needs as a driver of innovation. European Commission, September 2006.

European Commission. (2008) Pre-commercial procurement: driving innovation to ensure sustainable high quality public services in Europe. SEC(2007) 1668. Brussels, December 2007.

European Commission. (2011) Proposal for a directive of the European Parliament and of the Council on public procurement. Brussels, 20.12.2011, COM(2011) 896 final.

Flanagan, K., Uyarra, E., and Laranja, M. (2011) Reconceptualising the 'policy mix' for innovation. Research Policy, 40, 5, 702-713.

French, German and UK Governments. (2004) Towards and innovative Europe. A Paper by the French, German and UK Governments. 20th February 2004.

Fuchs, E.R.H. (2010) Rethinking the role of the state in technology development: DARPA and the case for embedded network governance. Research Policy, 39, 9, 1133-1147.

Gelderman, C.J., Ghijsen, P.W.T., and Brugman, M.J. (2006) Public procurement and EU tendering directives - explaining non-compliance. International Journal of Public Sector Management, 19, 7, 702-714.

Innovate UK (2012) Empowering people through technology. Innovation ideas, Spotlight on a current project \#30, T12/026 March 2012.

Knafl, K.A. and Howard, M.J. (1984) Interpreting and reporting qualitative research. Research in Nursing and Health, 7, 17-24.

Lember, V., Kattel, R., and Kalvet, T. (eds) (2014) Public Procurement, Innovation and Policy. International Perspectives. Heidelberg: Springer.

Link, A.N. and Scott, J.T. (2010) Government as entrepreneur: evaluating the commercialization success of SBIR projects. Research Policy, 39, 5, 589-601.

Martin, S., Hartley, K., and Cox, A. (1997) Public purchasing in the European Union: some evidence from contract awards. International Journal of Public Sector Management, 10, 4, 279-293.

McGarrah, R.E. (1987) The decline of U.S. manufacturers: causes and remedies. Business Horizons, 30, 6, 5967.

Miles, I. (2007) Research and development (R\&D) beyond manufacturing: the strange case of services R\&D. $R \& D$ Management, 37, 3, 25-36.

Morand, P.-H. (2003) SMEs and public procurement policy. Review of Economic Design, 8, 301-318.
Mowery, D.C. and Simcoe, T. (2002) Is the Internet a US invention? - an economic and technological history of computer networking. Research Policy, 31, 1369-1387.

NL Agency. (2011) SBIR. The power of public procurement: innovative solutions to societal challenges. NL agency, The Hague. Publication-nr. 3SBIR1002.

OECD. (2011) Demand-Side Innovation Policies. Paris: OECD Publishing.

Quintas, P. and Guy, K. (1995) Collaborative, precompetitive R\&D and the firm. Research Policy, 24, $325-348$.

Roos, A. (2009) SBIR in the Netherlands: a new perspective for Europe? Available: http://www.ec.europa.eu/ enterprise/policies/innovation/policy/lead-market -initiative/files/nl_sbir_en.pdf (last access July 2011).

Roos, A. (2011) Pre-commercial procurement in the Netherlands: SBIR. European Conference on Public Procurement of Innovation: Facing Societal Challenges Delivering Better Public Services \& Supporting SMEs To Innovate. 27-28 June 2011, Torino, Italy.

Rothwell, R. (1986) Public innovation policy: to have or to have not? R\&D Management, 16, 25-36.

Sloth, M. (2011) WP 2 - analysis of public pre-commercial procurement models and mechanisms. P3ITS - precommercial pblic procurement for Intelligent Transport Systems and Services innovation and deployment. Project financially supported by the 7th FP. Project number 248659.

Small Business Innovation Development Act. (1982) Public Law 97-219-July 22, 1982.

Smith, R.P. (1990) Defence procurement and industrial structure in the UK. International Journal of Industrial Organization, 8, 185-205.

Smits, R. and Kuhlmann, S. (2004) The rise of systemic instruments in innovation policy. International Journal of Foresight and Innovation Policy, 1, 4-32.

Smits, R., Kuhlmann, S., and Shapira, P. (2010) The Theory and Practice of Innovation Policy. An International Research Handbook. Cheltenham: Edward Elgar.

Technology Strategy Board. (2011) SBRI assistive technology competitions - invitation to tender. Available: http:// www.innovateuk.org/content/competition/making-waves -gesture-based-communications-system.ashx (last access October 2012).

Vinnova. (2007) Public procurement as a driver for innovation and change. Report on government commission to Nutek and VINNOVA. VP 2007:03.

Vonortas, N.S., Bhatia, P., and Mayer, D.P. (2011) Public Procurement and Innovation in the United States. Washington, DC: Elliot School of International Affairs, George Washington University.

Wallsten, S.J. (2000) The effects of government-industry $R \& D$ programs on private $R \& D$ : the case of the Small Business Innovation Research program. Rand Journal of Economics, 31, 1, 82-100.

Wessner, C.W. (2008) An Assessment of the SBIR Program. National Research Council. Committee on Capitalizing on Science, Technology, and Innovation. Washington, DC: National Academies Press. 
Wieczorek, A.J. and Hekkert, M. (2012) Systemic instruments for systemic innovation problems: a framework for policy makers and innovation scholars. Science and Public Policy, 39, 74-87.

\section{Notes}

1. The following activities fall within the definition of R\&D: basic research, industrial research, experimental development and the production of a limited 0-series (see EC 2006/C 323/01 and COM/2007/799). 'R\&D does not include commercial development activities such as production, supply to establish commercial viability or to recover R\&D costs, integration, customization, incremental adaptations and improvements to existing products or processes' (European Commission, 2008, pp. 2-3).

2. Article 16f, included in the directive for public authorities (2004/18/EC), and Article 24e of the public procurement directive for utilities (2004/17/EC) state that these directives do not apply to 'research and development services other than those where the benefits accrue exclusively to the contracting authority/entity for its use in the conduct of its own affairs, on condition that the service provided is wholly remunerated by the contracting authority/entity'. In December 2011, the European Commission launched a proposal for a new directive to the European Parliament on public procurement (European Commission, 2011). This is the outcome of discussions on the regulations for public procurement in the EU (Martin et al., 1997; Bovis, 1998; Morand, 2003; Gelderman et al., 2006).

3. http://www.greenov.net/@api/deki/files/440/=Public _Procurement_of_Innovation_conference\%252C _Turin_27-28_June\%252C_Agenda.pdf (last access October 2012).

4. For other PCP cases, see: http://cordis.europa.eu/fp7/ ict/pcp/projects_en.html (last access October 2013).

5. See: http://cordis.europa.eu/fp7/ict/pcp/msinitiatives _en.html (last access October 2013).

6. As a matter of fact, the Frascati manual does not include this type of targeted R\&D support among the indicators that are collected to assess R\&D capabilities and related activities.

7. This is a point of contrast with the US program, which essentially mandates that $2 \%$ of federal agency R\&D budgets must be directed to small firms, which are supposed to carry out R\&D projects and activities to support agency missions (Vonortas et al., 2011).

8. Alert Solutions was founded in 2007 and had two employees during the involvement in the DigiDijk project. The company had established cooperation with well-known companies like GeoDelft and 2M Engineering Ltd. Hansje Brinker was a spin-off of TU Delft, also founded in 2007 and with two employees at the time of the DigiDijk project (Roos, 2009).

9. http://www.dius.gov.uk/policy/SBRI.html (last access October 2012).
10. http://www.innovateuk.org/content/competition/making -waves-gesture-based-communications-system.ashx (last access October 2013).

11. The proposals also needed to meet the following functional specifications: accessible and usable, discreet, robust and transferable, responsive, based on locationbased technologies, adaptable to/sustainable with technological developments, simplified use, online and offline usage, built-in help, and guidance for usability issues (Technology Strategy Board, 2011).

12. http://www.scoop.it/t/sensory-impairment-solutions/ $\mathrm{p} / 2449781917 /$ inclusion-in-elearning-blog (last access October 2013).

13. https://www.innovateuk.org/documents/1524978/181 2835/Empowering+people+through+technology+-+ case+studies/6d0a2bc3-c04f-400e-91c9-7c3f5817513e (last access October 2012).

14. http://www.egov.vic.gov.au/victorian-government -resources/case-studies-victoria/vps-innovation-case -studies/smart-smes-market-validation-program-vps -innovation-case-study.html (last access October 2013).

15. For some of these TRS and the companies that submitted feasibility studies, see: http://www.treadstone.com .au/commercialisation-australia-round-2-recipients-11 -success-stories/ (last access September 2011).

16. For details of the granted proof of concepts in this second round, see: http://www.business.vic.gov.au/industries/ science-technology-and-innovation/programs/driving -business-innovation/market-validation-program (last access October 2013).

17. One of the reasons for the lack of scholarly discussion of PCP may be that in academic environments, PCP is regarded as a new branding or buzzword referring to the traditional procurement of $R \& D$ results, a field where several contributions can be found (Rothwell, 1986; McGarrah, 1987; Smith, 1990; Mowery and Simcoe, 2002; Miles, 2007; Fuchs, 2010; Vonortas et al., 2011).

18. The public agency can share the $R \& D$ results with other public authorities and industry through publication and standardization, as well as through their commercialization (European Commission, 2008, p. 7). The public purchaser can also demand a free license to use the R\&D results for internal use (ibid).

19. In regular public procurement, a public organization buys ready-made products 'off the shelf' (Edquist and Zabala-Iturriagagoitia, 2012).

20. For a detailed analysis of mixes of innovation policy instruments, see Borrás and Edquist (2013).

21. PPI occurs when a public organization places an order for a product that does not exist at the time (Edquist and Zabala-Iturriagagoitia, 2012).

Charles Edquist is Holder of the Ruben Rausing Chair in Innovation Research at CIRCLE, Lund University (Sweden) since February 2003. He is one of the founders and the first director (2004-2011) of 
CIRCLE (Centre for Innovation, Research and Competence in the Learning Economy) at Lund University, which by 2011 had developed into one of the largest innovation research centers in Europe, and a leading international center for research and advice on $\mathrm{R} \& \mathrm{D}$, innovation, knowledge creation, entrepreneurship and economic dynamics. Previously he held a Chair at the University of Linköping (Sweden). His comprehensive list of publications include books and articles on innovation processes, innovation systems, innovation policy and governance of innovation systems. He has a long experience in evaluations of innovation systems and innovation policy, as well as consultancy tasks with numerous international organizations such as OECD, UNIDO, EU, UNCTAD, ILO, UNDP, UNESCO, to mention a few.
Jon Mikel Zabala-Iturriagagoitia is a post-doc researcher at the Deusto Business School, DonostiaSan Sebastian (Spain). He graduated as engineer in industrial organization at the University of Mondragon (2002) and holds a European PhD in Engineering and Innovation Projects from the Polytechnic University of Valencia (2008). His research focuses on innovation policy, policy evaluation, innovation systems and innovation management tools. He has been member of the Institute of Innovation and Knowledge Management (INGENIO), joint Institute of the Spanish Council for Scientific Research (CSIC) and the Polytechnic University of Valencia (UPV), visiting researcher at the Technical Research Centre of Finland (VTT) and post-doc researcher at CIRCLE, Lund University (Sweden). 